\title{
ATESTADOS DE CAPACIDADE TÉCNICA E HABILITAÇÃO EM LICITAÇÕES PÚBLICAS
}

\author{
Cynara Monteiro Mariano*
}

É comum nos atos convocatórios das licitações públicas o elencamento de exigências pormenorizadas e excessivas quanto à idoneidade financeira e capacidade técnica e operacional das empresas licitantes.

A Administração Pública, ao elaborar os Editais dos certames licitatórios, segue fielmente os termos da Lei $n^{\circ} 8.666 / 93$, cujos dispositivos, no tocante a essas exigências, são de duvidosa constitucionalidade.

É sabido, inclusive, que por motivos escusos e atentadores à moralidade pública, as licitações, não raras vezes, são visivelmente destinadas apenas às empresas de grande porte ou mais antigas no ramo de prestação de serviços.

Assim é que, em repúdio às licitações "dirigidas", por abrigarem uma série de requisitos de capacidade técnica e financeira que somente as grandes empresas podem satisfazer, alijando-se do certame licitatório, portanto, as empresas de pequeno e médio porte ou as iniciantes no ramo de prestação de serviços, comentaremos alguns aspectos relativos à uma das exigências mais comuns nos editais de convocação, a saber, os atestados de capacidade técnica.

Importa esclarecer que nosso objeto de estudo tratará especificamente das licitações para contratação de empresas especializadas no ramo da prestação de serviços.

Ressalvamos, ainda, que não contemplaremos as disposições da Medida Provisória $n^{\circ} 2.026$, que instituiu, no âmbito da União, modalidade de licitação denominada pregão para a aquisição de bens e serviços comuns.

Primeiro porque referida modalidade há de ser utilizada apenas em licitações de âmbito federal; segundo porque, de acordo com a exegese do art. $3^{\circ}$, inciso I, da referida MP, ao exigir a autoridade competente os requisitos indispensáveis à habi-

* Advogada licenciada, Membro da Comissão de Defesa do Consumidor da OAB/CE, também licenciada, e Assessora de Juiz do TRF da 5’ Região.

R. Dir. Adm.,

Rio de Janeiro, 222: 133-141,

out./dez. 2000 
litação no certame, certamente ela o fará nos termos da Lei n 8.666/93, como, aliás, faculta o seu art. $9^{\circ}$

Apenas para melhor elucidar o assunto, cumpre esclarecer que bens e serviços comuns, para fins da Medida Provisória $n^{\circ}$ 2.026, são aqueles "cujos padrões de desempenho e qualidade possam ser objetivamente definidos pelo edital, por meio de especificações usuais no mercado" (art. $1^{\circ}, \S 1^{\circ}$ ).

Sendo assim, o assunto de que cuidaremos no presente ensaio pode vir a ser objeto de uma licitação pregão, entretanto, as considerações a que nos propomos, como se disse acima, servem de reflexão para possíveis inconstitucionalidades a serem observadas também nessa nova modalidade.

A) Breves comentários sobre a questão das exigências indispensáveis ao cumprimento das obrigações.

Os Editais de licitações públicas, via de regra, exigem, como critério de auferição da capacidade técnica das empresas, atestados fornecidos por pessoas de direito público ou privado para os quais o licitante esteja prestando ou tenha prestado serviço compatível em características, quantidades e prazos com o objeto da licitação, em conformidade com o que preconiza a Lei ${ }^{\circ} 8.666 / 93$ (art. 30, inciso II).

$A b$ initio, vale dizer que o Edital, destinado a normatizar o desenvolvimento e o regime da futura relação contratual, deve estabelecer as condições a serem preenchidas pelos licitantes para a participação no certame, indicando os elementos a serem apresentados para a demonstração de seu atendimento.

Todavia, sucede que, levando-se em conta que o Edital é um ato administrativo normativo e, portanto, infra-legal, não possui, pois, o condão de estabelecer restrição não levada a termo pela Constituição Federal, sob pena de subverter inteiramente a ordem jurídica vigente, pelo o que resta indubitável a inconstitucionalidade das normas que consignam exigências dessa espécie.

A Carta Magna de 1988 dispõe, incisivamente, em seu art. 37, inciso XXI, que:

"ressalvados os casos especificados na legislação, as obras, serviços, compras e alienações serão contratados mediante processo de licitação pública que assegure igualdade de condições a todos os concorrentes, com cláusulas que estabeleçam obrigaçōes de pagamento, mantidas as condiçōes efetivas da proposta, nos termos da lei, o qual somente permitirá as exigências de qualificação técnica e econômica indispensáveis à garantia do cumprimento das obrigações."

De sorte que, pela leitura do dispositivo constitucional supra aludido, chega-se facilmente à ilação de que há, no nosso ordenamento jurídico, expressa previsão proibitiva quanto ao estabelecimento de exigências de qualificação técnica e econômica que não sejam indispensáveis à garantia do cumprimento das obrigações.

Logo, quando a norma editalícia impõe, como requisitos de qualificação técnica ou econômica para fins de habilitação dos licitantes, exigências outras que não as indispensáveis à garantia do cumprimento das obrigações, as disposições contidas no ato convocatório revestem-se de inconstitucionalidade. 
Isto porque tais exigências podem consistir num rigorismo excessivo, incoerente, portanto, com a fase de habilitação, que é um procedimento sumário, no qual, como a própria Constituição Federal determina, somente poderão ser exigidas as condições indispensáveis à garantia do cumprimento das obrigações da futura relação contratual.

Nesta fase (a da habilitação), deve ser exigida apenas a documentação estritamente necessária à comprovação da qualificação técnica e econômica dos licitantes, de modo a propiciar a participação de um maior continente de proponentes e, consequientemente, selecionar, com maior segurança, a proposta que mais atenda ao interesse público.

Caso contrário, ou seja, se a Administração exceder os requisitos de habilitação, exorbitando sua faixa discricionária, estará ilegalmente restringindo a possibilidade de ofertar.

Portanto, imposições editalícias excessivas afrontam o princípio basilar do procedimento licitatório, qual seja, o da universalidade, isto é, o de possibilitar a participação do maior número de licitantes, agredindo ainda o princípio constitucional da igualdade ou isonomia, como se demonstrará a seguir.

B) Da exigência dos atestados de capacidade técnica em quantidades, características e prazos idênticos aos do objeto da licitação. Violação às normas constitucionais e legais.

Quando o Edital exige, na fase de habilitação, atestados que comprovem a prestação de serviço anterior nas mesmas quantidades, características e prazos do objeto da licitação, costuma indicar em Anexos uma série de categorias de profissionais a serem atendidas, as respectivas quantidades e a necessária comprovação de experiência anterior da mão-de-obra a ser contratada.

Entretanto, admitir-se que os atestados de capacidade técnica comprovem a prestação de serviço em tais moldes significa atribuir à lei interpretação diversa do fim almejado pelo legislador.

Com efeito, a Lei $n^{\circ} 8.666 / 93$, em seu art. 30 , inciso II, estatui que:

"A documentação relativa à qualificação técnica limitar-se-á a:

I- omissis;

II - comprovação de aptidão para desempenho de atividade pertinente e compativel em características, quantidades e prazos com o objeto da licitação, e indicação das instalações e do aparelhamento e do pessoal técnico adequados e disponiveis para a realização do objeto da licitação, bem como da qualificação de cada um dos membros da equipe técnica que se responsabilizará pelos trabalhos;"

Como o próprio texto da lei diz, no tocante à qualificação técnica dos licitantes, deve-se exigir atestados que comprovem apenas a aptidão das empresas para o desenvolvimento de atividades pertinentes e compativeis ao objeto da licitação, ou seja, atividades similares.

Similaridade, por certo, não significa perfeita identidade de quantidade, como assim deseja grande parte dos atos convocatórios. 
E, por óbvio, o fato de se permitir a exigência de comprovação de realização de obras semelhantes com a do objeto licitado não implica na exigência de quantitativos mínimos ou máximos.

Ademais, a aptidão a que se refere a Lei $n^{\circ} 8.666 / 93$, em seu art. 30 , inciso II, significa habilidade técnica para o desempenho de atividade pertinente e compatível com o objeto da licitação, e não a execução anterior de objeto idêntico, ou seja, de serviço prestado por todos os profissionais porventura enumerados na norma editalícia.

Tanto é assim que esse mesmo diploma legal, em seu $\S 3^{\circ}$, estabelece que “sempre será admitida a comprovação de aptidão através de certidões ou atestados de obras ou serviços similares de complexidade tecnológica e operacional equivalente ou superior."

Isto quer dizer que, na fase habilitatória, os atestados que comprovem a prestação de serviço similar ao do objeto da licitação são suficientes para auferir a capacidade técnica dos licitantes, nomeadamente quando o objeto licitatório consiste na prestação de serviços de pequena monta, uma vez que à mão-de-obra a ser contratada não se exige grande especialização técnica nem mesmo formação superior, diversamente do que é exigido para as obras de engenharia, por exemplo.

Por outro lado, vale ressaltar que a prestação de serviço nas mesmas quantidades e características do objeto da licitação não se presta para auferir a capacidade técnica dos licitantes, posto que, nas palavras do jurista Carlos Ari Sundfeld, "a simples reunião caótica de profissionais, mesmo altamente especializados, não oferece garantia de que a empresa seja capaz de operar eficientemente, pois nada diz respeito quanto a sua estrutura administrativa, seus métodos organizacionais, seus processos internos de controle de qualidade, o entrosamento da equipe etc." '

Logo, é de se assinalar que o Edital somente pode exigir, segundo a exegese da própria Lei ${ }^{\circ} 8.666 / 93$, atestados de comprovação de serviço semelhante (entenda-se similar ao do objeto a ser contratado), sendo a exigência de perfeita identidade de características e quantidades, portanto, um rigorismo incoerente com a natureza da fase habilitatória que visa, conforme já salientado em linhas anteriores, a participação do maior número de licitantes.

E assim o é, além da análise do sentido teleológico da lei, porque a Administração Pública, ao exigir a comprovação de realização de serviços semelhantes, deve ficar submissa também ao princípio da razoabilidade, ou seja, as exigências editalícias devem guardar correlação lógica com o objeto licitado, devendo com este ser pertinentes e compatíveis, a fim de atender ao interesse público (finalidade do ato).

Cabe ao administrador público, em decorrência de seu poder discricionário, fixar os critérios para a comprovação por parte dos licitantes da capacidade técnica necessária à execução do objeto licitado. Esses critérios, contudo, devem ser harmonizados com a complexidade dos serviços. A exigência de que as empresas licitantes tenham executado serviços semelhantes ao objeto do certame é induvidosamente razoável, o mesmo não se podendo dizer, no entanto, das que estabelecem a execução de idêntico serviço objeto da licitação.

1 Licitações e Contratos Administrativos, Ed. Revista dos Tribunais, SP, 1999, p. 101. 
Portanto, vê-se que a exigência de atestados que comprovem a prestação de serviço anterior, nas mesmas características e quantidades do serviço objeto do certame, agride o preceito constitucional do art. 37, inciso XXI (" ressalvados os casos especificados na legislação, as obras, serviços, compras e alienações serão contratados mediante processo de licitação pública que assegure igualdade de condições a todos os concorrentes, com cláusulas que estabeleçain obrigações de pagamento, mantidas as condições efetivas da proposta, nos termos da lei, o qual somente permitirá as exigências de qualificação técnica e econômica indispensáveis à garantia do cumprimento das obrigações"), afigurando-se, ainda, exegese equivocada da lei, no caso da própria Lei que rege o procedimento das licitações públicas.

Quanto à questão dos prazos que a norma editalícia venha a indicar como comprovação da experiência anterior da mão-de-obra a ser contratada, observa-se que a exigência é feita, muitas vezes, mediante a obrigatoriedade da apresentação de "curriculum" detalhado dos profissionais, a demonstrar o período de experiência em serviço anterior igual ao do objeto da licitação.

Ora, a exigência quanto a períodos mínimos de experiência é manifestamente ilegal, por afrontar o disposto no art. $30, \S 5^{\circ}$ da Lei $n^{\circ} 8.666 / 93$ :

"É vedada a exigência de comprovação de atividade ou de aptidão com limitações de tempo ou de época ou ainda em locais especificos, ou quaisquer outras não previstas nesta Lei, que inibam a participação na licitação."

Em relação à obrigatoriedade de apresentação do "curriculum" de todos os profissionais indicados pelo Edital, esta é outra exigência inadequada para a fase de habilitação, pois se apresenta como rigorismo excessivo, que diz respeito somente à fase de contratação da licitante vencedora, e não à sua simples participação no certame.

Isto porque, havendo a exigência de que ora se trata, pode-se levar a crer que o administrador deseja que as empresas licitantes possuam todos esses profissionais no seu quadro permanente de empregados.

Entretanto, seria um absurdo admitir-se que a empresa deva ter como empregados os profissionais indicados pelo objeto da licitação, pois sua contratação, se for o caso, dar-se-á posteriormente à fase de habilitação, quando, após ultrapassadas as demais fases do procedimento licitatório, a licitante seja a vencedora no certame.

Ademais, não faz sentido também a empresa manter uma espécie de "reserva remunerada", ou seja, um contingente de empregados, gerando despesas com salários e encargos sociais, apenas para poder se habilitar na licitação.

Por outro lado, observa-se que a Administração Pública, ao exigir a apresentação de "curriculum" dos profissionais, de acordo com as especificações a serem indicadas nas normas editalícias, na verdade, pretende escolher o pessoal para executar o serviço objeto da licitação.

Acontece que a escolha do pessoal cabe à empresa vencedora. Não se trata, pois, de concurso público de provas e títulos, onde a Administração escolhe o mais apto. Permitir o contrário importa em afronta ao princípio da moralidade adminis- 
trativa, uma vez que se transfere para o Poder Público função própria da licitante contratada, qual seja, a de escolher seu pessoal.

À Administração cabe apenas exigir a qualificação profissional imposta por lei.

E é justamente a lei, no caso a de $n^{\circ} 8.666 / 93$, que estabelece a vedação à Administração em escolher os profissionais que vão executar o objeto do certame, senão vejamos:

“Art. $7^{\circ}, \S 5^{\circ} . \hat{E}$ vedada a realização de licitação cujo objeto inclua bens $e$ serviços sem similaridade ou de marcas, características e especificaçōes exclusivas, salvo nos casos em que for tecnicamente justificável, ou ainda quando o fornecimento de tais materiais e serviços for feito sob o regime de administração contratada, previsto e discriminado no ato convocatório."

Esclareça-se, ainda, que nem nas compras a Administração pode escolher a marca do bem (art. $15, \S 7^{\circ}$, I da Lei $N^{\circ} 8.666 / 93$ ), o que não dizer, então, de selecionar pessoas.

$\mathrm{Na}$ verdade, o que se verifica em exigências como a que se está a comentar é uma tentativa da Administração Pública em frustar o caráter competitivo da licitação.

Ao exigir a apresentação de atestados de serviços prestados nas mesmas quantidades e categorias de profissionais indicados e o "curriculum" de todos eles, inclusive com quantitativos mínimos ou máximos de experiência profissional, percebe-se que se está destinando a licitação somente às empresas de grande porte, pois, às de pequeno porte, como é óbvio, é impossível o atendimento dessas exigências.

Em prosperando requisitos como esses nos atos convocatórios, estar-se-á permitindo a desnaturação do procedimento licitatório, mormente de sua fase de habilitação, que visa a participação do maior número de licitantes com vistas à seleção da proposta mais vantajosa ao interesse público.

Vale lembrar que todas as empresas têm o direito subjetivo público de participar de licitações, em igualdade de condições; é o que prega o princípio da isonomia ou igualdade, inserto no art. $5^{\circ}$, caput, da Carta Política de 1988.

O princípio, já dos tempos do filósofo Aristóteles, significa que os iguais devem ser tratados de modo igual, e os desiguais, de modo desigual.

Nessa linha é que, por exemplo, a CF/88 estabelece, no art. 170, inciso IX, "tratamento favorecido para as empresas de pequeno porte constituídas sob as leis brasileiras e que tenham sua sede e administração no País."

Assim, se a Administração pretende que as exigências dos atestados de capacidade técnica sejam atendidas nos termos em que os atos convocatórios estão a estabelecer nos dias atuais - quantidades, características e prazos idênticos aos do objeto da licitação - e como tais requisitos somente podem ser cumpridos pelas empresas de grande porte, ela deve sempre tratar no Edital, de modo diverso e específico, as condições a serem preenchidas pelas empresas de menor porte.

De sorte que, quanto às empresas iniciantes, que não pudessem comprovar, por exemplo, a apresentação de Balanço Patrimonial e Demonstração de Resultados do exercício do ano em que se constituíram, como também exigem os Editais, deve-lhes ser dispensada tal documentação. 
Isto porque, consoante o princípio da igualdade, essas empresas fazem jus a um tratamento jurídico diferenciado, que não se confunde, esclareça-se, com tratamento jurídico privilegiado.

É de se ressaltar ainda outra disposição da Constituição de 1988 que diz respeito ao tratamento diferenciado às micro, pequenas e média empresas, lapidado no artigo 179:

"A União, os Estados, o Distrito Federal e os Municípios dispensarão às microempresas e às empresas de pequeno porte, assim definidas em lei, tratamento juridico diferenciado, visando a incentivá-las pela simplificação de suas obrigações administrativas, tributárias, previdenciárias e creditícias, ou pela eliminação ou redução destas por meio de lei."

Pela interpretação sistemática de nossa Lei Maior, vê-se que o que pretendeu o constituinte foi mesmo simplificar as obrigações das pequenas empresas. E quanto aos procedimentos licitatórios, a simplificação fica por conta da habilitação dessas empresas, vez que, não raro, fica inviabilizada pela impossibilidade de atender às inúmeras exigências das normas editalíciais.

Um exemplo da simplificação da participação das pequenas empresas em licitações foi a previsão, no artigo 225 da Constituição do Estado do Rio de Janeiro, que, em seu inciso III, estabelece "habilitação sumária e procedimentos simplificados para participação em licitações públicas, bem como 'preferência' na aquisição de bens e serviços de valor compatível com o porte das micro e pequenas empresas".

De fato, admitir que apenas empresas de grande porte participem de um procedimento licitatório atenta contra os princípios que regem a atividade econômica, nomeadamente o da livre iniciativa e o da livre concorrência (art. 170, inciso IV).

Parece forçoso concluir que não há como se garantir a livre concorrência entre as empresas quando uma licitação pública se encontra destinada a determinados candidatos.

Nossos tribunais, inclusive, de há muito combatem a discricionariedade e a arbitrariedade utilizadas nos processos licitatórios que visam um esvaziamento do número de participantes, de modo a privilegiar a participação das grandes empresas em detrimento das pequenas e médias, mantendo mansa e pacífica jurisprudência sobre a matéria, exempli gratia:

"Nulo é o Edital omissos em pontos essenciais ou que contenham condições discriminatórias ou preferenciais, que afastem determinados interessados e favoreçam outros" (TFR, RT 228/549, RDA 37/298, STF 57/306, RDA 26/235 e 32/224).

"Não se compadece com o princípio de igualdade entre os licitantes, a exigência em Edital de processo licitatório, que vise a restringir o número de concorrentes" (Ementa n' 7893353, Ap. em MS n' 111.638 - RN, D.J.U em 25.09.86 Rel. Min Costa Lima). 
Vê-se, então, de forma clara, que as exigências estabelecidas nas normas editalícias quanto aos atestados de capacidade técnica, de quantidades, características e prazos idênticos aos do objeto da licitação, agridem frontalmente o princípio da igualdade, uma vez que, ao contemplar as já multireferidas exigências, o administrador exclui todas as empresas de médio e pequeno porte, inclusive, as que estão ingressando no campo da prestação de serviços, sem lhes dar a menor possibilidade de concorrerem com licitantes de maior porte ou mais antigas nesse ramo.

Por isso é que, justamente no intuito de evitar essa discriminação e assegurar o cunho competitivo das licitações, a Lei $n^{\circ} 8.666 / 93$, em seu art. $3^{\circ}$ e $\S 1^{\circ}$, I, estabelece o seguinte:

"Art. 30. A licitação destina-se a garantir a observância do princípio constitucional da isonomia e a selecionar a proposta mais vantajosa para a administração e será processada e julgada em estrita conformidade com os principios básicos da legalidade, da impessoalidade, da igualdade, da publicidade, da probidade administrativa, da vinculação ao instrumento convocatório, do julgamento objetivo e dos que são correlatos.

$\S 1^{\circ}$. É vedado aos agentes públicos:

I-admitir, prever, incluir ou tolerar, nos atos de convocação cláusulas ou condições que comprometam, restrinjam ou frustem o seu caráter competitivo e estabeleçam preferências ou distinções em razão da naturalidade, da sede ou do domicílio dos licitantes ou de qualquer outra circunstância pertinente ou irrelevante para o específico objeto do contrato."

Portanto, o legislador, tanto o constitucional quanto o ordinário, como se viu, ao repudiar exigências desnecessárias à comprovação da capacidade técnica dos licitantes, para fins de habilitação, assim o fez com vistas à propiciar a ampla participação das empresas, em igualdade de condições.

Segundo o inesquecível Mestre do Direito Administrativo Pátrio, Hely Lopes Meirelles, "o que o princípio da igualdade entre os licitantes veda é a cláusula discriminatória ou julgamento faccioso que desiguala os iguais ou iguala os desiguais, favorecendo a uns e prejudicando a outros, com exigências inúteis para o serviço público, mas com destino certo a determinados candidatos." ${ }^{2}$

Em conclusão, pode-se inferir que as normas editalícias que abrigam as exigências objeto de nosso estudo - atestados de capacidade técnica que comprovem a prestação de serviço em idênticas quantidades, características e prazos do objeto licitado, bem como "curriculum" detalhado de todos os profissionais, a indicar o período de experiência em serviço anterior igual ao desse mesmo objeto - contrariam garantias fundamentais asseguradas às empresas (livre concorrência) e aos

2 Direito Administrativo Brasileiro, 18ª Edição, Ed. Malheiros, 1993, p. 67. 
cidadãos (igualdade) pela Constituição da República e o conteúdo finalístico das normas que regem o procedimento das licitações públicas, e por isso merecem ser expurgadas da corriqueira prática da elaboração de Editais que se vê nos dias de hoje.

\section{Bibliografia}

1. SUNDFELD, Carlos Ari - Licitações e Contratos Administrativos, Ed. Revista dos Tribunais, SP, 1999, pgs. 101 e 125.

2. MEIRELLES, Hely Lopes - Direito Administrativo Brasileiro, $18^{\star 2}$ edição, Ed. Malheiros, 1993, p. 67. 


\section{O Orçamento na Constituição}

Ricardo Lobo Torres

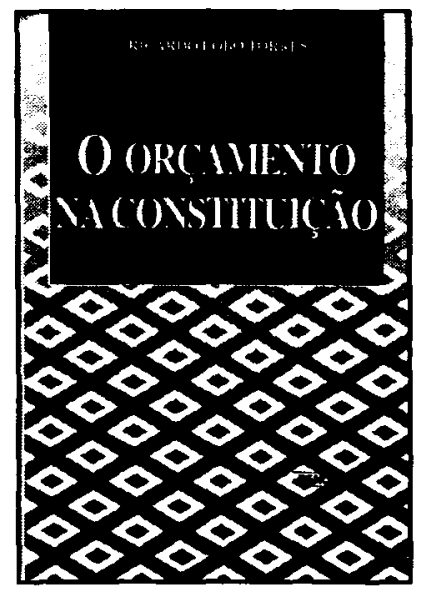

O orçamento, do ponto de vista jurídico, deixa de ser apenas o instrumento de previsão da receita $e$ de autorização dos gastos públicos em um sistema financeiro aberto para os empréstimos. É, sobretudo, o documento de qualificação dos valores éticos, a conta corrente dos princípios constitucionais, o plano contábil da justiça social, o balanço das escolhas dramáticas por políticas públicas em um universo fechado de recursos financeiros escassos $e$ limitados.

$\begin{array}{lll}\text { Ref. } 0084 & \text { Brochura } & 407 \text { págs. } \\ \text { Form. 14x21 } & 1999 & 2 \text { ed. }\end{array}$

\section{O Processo de Execução}

Este livro, resultante da pesquisa acadêmica do autor, representa um ensaio de revisão teórica e prática do processo de execução, a partir das premissas da efetividade do processo, para, seguindo a tendência mais recente verificada em outros sistemas processuais, assentar uma rede sólida de princípios indispensáveis à interpretação e aplicação das normas que o disciplinam, contribuindo ainda para o aprofundamento dos estudos de uma mais profunda e almejada reforma processual.

Leonardo Greco

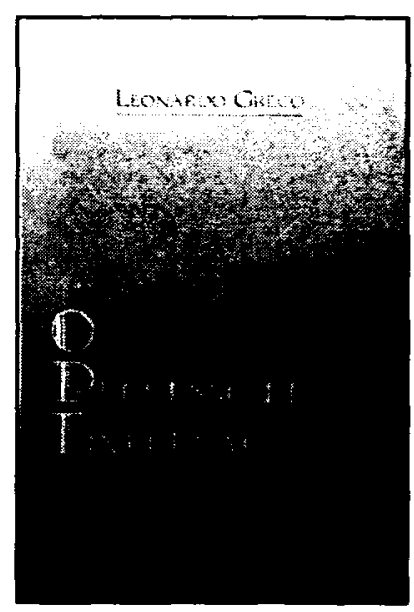

Ref. 0225

Encadernado 440 págs.

Form. 16x23 1999 